\title{
Effect of body tilting on physiological functions in stable very low birthweight neonates
}

\author{
Heracles D Dellagrammaticas, John Kapetanakis, Maria Papadimitriou, George Kourakis
}

\begin{abstract}
In babies of very low birth weight $(<1500 \mathrm{~g})$ we studied the effect of head up tilting on oxygenation, respiratory rate, heart rate and blood pressure $(n=23)$, on gastric emptying $(n=10)$, and on weight gain $(n=6)$. Head up tilting to $45^{\circ}$ achieved the best oxygenation at the angles studied, and decreased the respiratory and heart rates; there was no significant change in blood pressure. Residue in the stomach was also significantly less at $45^{\circ}$, and the neonates' weight gain was higher.

We conclude that nursing stable very low birthweight infants with a higher head up tilt than is conventional may have some advantages.
\end{abstract}

Except for short periods, humans spend most of their time in the vertical rather than the horizontal position. Although posture is known to affect physiological functions such as lung mechanics and perfusion, ${ }^{12}$ and gastric emptying, ${ }^{3}$ these have mainly been studied in the prone and supine positions and little is known of the effects that postural changes in the vertical plane (tilting) may have on certain functions in either term ${ }^{5}$ or very low birthweight infants. ${ }^{6}$ Stable preterm neonates are conventionally nursed prone with a slight head up tilt, presumably to avoid regurgitation and aspiration of feeds.?

The purpose of the present study was to work out systematically the effect of head up tilting at various angles on oxygenation, respiratory and heart rates, blood pressure, gastric emptying, and weight gain in stable, preterm, very low birthweight neonates.

\section{Patients and methods}

We studied stable very low birthweight $(<1500$ g) preterm neonates who had not developed respiratory problems, were being fed normally, and were free from disease. Their gestational age was estimated from maternal dates, ultrasound scans, and a scoring system using physical criteria. ${ }^{8}$ Parental consent to participation in the study was obtained on all occasions.

The study consisted of three parts: part 1 was a study of oxygenation at $0^{\circ}, 10^{\circ}, 20^{\circ}, 30^{\circ}$, and $45^{\circ}$, and of respiratory rate, heart rate and blood pressure at $0^{\circ}$ and $45^{\circ}$; part 2 a study of gastric emptying at $10^{\circ}$ and $45^{\circ}$; and part 3 a study of weight gain at $10^{\circ}$ and $45^{\circ}$.

The detailed methods were as follows:
PART 1

To study the variables mentioned previously each neonate was placed in an open air intensive care incubator (Ohmeda) and the tilts achieved by modifying the tilting mechanism of the incubator as required. The neonates were secured in the prone position with a special sling and were supported appropriately. In most instances they were fully clothed and covered with a plastic sheet in order to minimise heat and water losses.

Oxygenation was evaluated using a calibrated transcutaneous electrode (Tc Ml Radiometer) set at $44^{\circ} \mathrm{C}$ and placed over the interscapular area. The results provided by the instrument used were expressed in $\mathrm{mm} \mathbf{H g}$ (conversion factor to SI units: $1 \mathrm{~mm} \mathrm{Hg}=0.133 \mathrm{kPa}$ ). Respiratory and heart rates were assessed using a cardiorespiratory monitor (Neoscope, Simonsen and Weel). Blood pressure was measured with a non-invasive oscillometric blood pressure monitor (Dinamap 847, Critikon) and disposable cuffs.

Ten readings of the transcutaneous oxygen monitor were obtained at 30 seconds intervals on each neonate at each tilt (angle). After each change of angle from $0^{\circ}$ to $45^{\circ}$ and back to $0^{\circ}$ there was a 10 minute interval before readings at the new angle were recorded. Readings were obtained in a similar fashion at $0^{\circ}$ angle 30 minutes after completing the readings on the return to the $0^{\circ}$.

Together with transcutaneous oxygen readings at $0^{\circ}$ and $45^{\circ}, 10$ readings of the respiratory and heart rates at 30 seconds intervals were also obtained on each neonate as well as five readings of the blood pressure at one minute intervals.

Particular care was taken that the readings should be obtained when the neonates were relaxed and asleep. As oxygenation is affected by the state of the neonate, care was taken to try and monitor the infants so they were studied during quiet sleep if possible, using the criteria by Prechtl. ${ }^{9}$ No other devices such as electrooculograms were used. The readings were obtained two hours after the last feed, and the neonates were not disturbed during the assessment. The neonates were not receiving any medication that could potentially affect the respiratory performance or the heart rate such as xanthines.

\section{PART 2}

Gastric emptying was assessed at $10^{\circ}$ and $45^{\circ}$ using the incubator and with the neonates secured in the prone position as described in part 1. The $10^{\circ}$ angle was chosen as it closely 
corresponded to the head up tilt used after a feed in many neonatal units. The gastric emptying was assessed by estimating the residue in the stomach 30 minutes after the standard meal and the dilutional method described in detail by $\mathrm{Yu}^{3}$ To estimate the stomach residue the concentration of phenol red used as a marker was measured spectrophotometrically in the stomach aspirates by a technician in the hospital laboratory who was not otherwise taking part in the study. Each infant studied was given the test meal first at the $10^{\circ}$ and then at the $45^{\circ}$ angle on the 10th day of life.

\section{PART 3}

The effect of head tilting on weight gain was assessed at $10^{\circ}$ and $45^{\circ}$. Weekly weight gain was assessed during the third, fourth, and fifth weeks of life, by which time the neonates had established a steady weight gain. They were fed on a special preterm formula (Alprem, Nestlé) and received $180 \mathrm{ml} / \mathrm{kg} /$ day. They were nursed in the same way as those in part 1 and were continuously kept at either $10^{\circ}$ or $45^{\circ}$ for each of the study weeks. Two sequences were followed in order to have a crossover design. A: third week $=10^{\circ}$, fourth week $=45^{\circ}$, and fifth week $=$ $10^{\circ}$; and B: third week $=45^{\circ}$, fourth week $=10^{\circ}$, and fifth week $=45^{\circ}$.

\section{Results}

Because of technical problems the study was conducted during different periods of time, which resulted in different neonates being included in the three parts of the study.

PART 1

Twenty three neonates were included in this part of the study. Median birth weight was 1350 g (range 800-1490), median gestational age 30 weeks (range 26-34) and male to female ratio $1 \cdot 5: 1$. From the analysis of the recordings of transcutaneous oxygen tension, heart rate, respiratory rate, and blood pressure there was no obvious trend of values for any of these variables in any neonate within each set of values for a given tilt. It was therefore thought to be statistically acceptable to average the set of values obtained for each variable from each neonate for each angle (table 1). The results for the group as a whole for each variable for each tilt were expressed as mean (SD).

In all neonates oxygenation improved as the angle of the tilt increased from $0^{\circ}$ to $45^{\circ}$; for each neonate the best oxygenation was achieved at $45^{\circ}$. The difference in oxygenation (expressed as difference between means) for the group at all tilts, taking as the point of reference the mean oxygenation ( 0 difference) at the $0^{\circ}$ angle, is shown in the figure. The difference between the mean transcutaneous oxygen tension at $0^{\circ}$ and $45^{\circ}$ was $13.5 \mathrm{~mm} \mathrm{Hg}(95 \%$ confidence interval (CI) 11.4 to $15.7 \mathrm{~mm} \mathrm{Hg}$; $\mathrm{p}<0.01$ by paired Student's $t$ test) (figure)

The respiratory rates and heart rates consistently decreased in all neonates when the angle of tilt increased from $0^{\circ}$ to $45^{\circ}$; there were no significant or consistent changes in blood pressure (table 1). The changes in respiratory and heart rates of the group were significant using a paired $t$ test. Means and $95 \%$ CI were $8.4(95 \%$ CI 6.8 to 10.0$)$ and $4 \cdot 17(96 \%$ CI 3.2 to $5 \cdot 2)$, respectively $(\mathrm{p}<0.01)$.

PART 2

The gastric residue at 30 minutes was assessed in 10 neonates. Median birth weight was $1405 \mathrm{~g}$ (range 800-1490), median gestational age 31 weeks (range 27-34) and male to female ratio $2 \cdot 3: 1$. In all neonates there was a consistent

Table 1 Oxygenation, respiratory rate, heart rate and blood pressure (expressed as mean value of the 10 readings/tilt) for each of the 23 neonates studied in part 1

\begin{tabular}{|c|c|c|c|c|c|c|c|c|c|c|c|c|c|c|c|}
\hline \multirow{3}{*}{$\begin{array}{l}\text { Case } \\
\text { No }\end{array}$} & \multicolumn{7}{|c|}{ Oxygenation $(\mathrm{mm} \mathrm{Hg})^{*}$} & \multicolumn{2}{|c|}{ Respiratory rate } & \multicolumn{2}{|c|}{ Heart rate } & \multicolumn{4}{|c|}{ Blood pressure } \\
\hline & \multirow[t]{2}{*}{$\overline{\sigma^{\circ}}$} & \multirow[t]{2}{*}{$10^{\circ}$} & \multirow[t]{2}{*}{$20^{\circ}$} & \multirow[t]{2}{*}{$30^{\circ}$} & \multirow[t]{2}{*}{$45^{\circ}$} & \multirow[t]{2}{*}{$0^{\circ}$} & \multirow[t]{2}{*}{$0^{\circ}$} & \multirow[t]{2}{*}{$\infty^{\circ}$} & \multirow[t]{2}{*}{$45^{\circ}$} & \multirow[t]{2}{*}{$0^{\circ}$} & \multirow[t]{2}{*}{$45^{\circ}$} & \multicolumn{2}{|l|}{$\sigma^{\circ}$} & \multicolumn{2}{|l|}{$45^{\circ}$} \\
\hline & & & & & & & & & & & & Systolic & Diastolic & Systolic & Diastolic \\
\hline $\begin{array}{r}1 \\
2 \\
3 \\
4 \\
5 \\
6 \\
7 \\
8 \\
9 \\
10 \\
11 \\
12 \\
13 \\
14 \\
15 \\
16 \\
17 \\
18 \\
19 \\
20 \\
21 \\
22 \\
23\end{array}$ & $\begin{array}{l}60 \cdot 6 \\
56 \cdot 9 \\
68 \cdot 4 \\
53 \cdot 9 \\
52 \cdot 1 \\
53 \cdot 8 \\
68 \cdot 6 \\
58 \cdot 1 \\
57 \cdot 2 \\
54 \cdot 2 \\
53 \cdot 7 \\
53 \cdot 7 \\
58 \cdot 6 \\
77 \cdot 0 \\
52 \cdot 4 \\
56 \cdot 1 \\
73 \cdot 1 \\
71 \cdot 8 \\
70 \cdot 4 \\
78 \cdot 4 \\
65 \cdot 9 \\
72 \cdot 0 \\
59 \cdot 7\end{array}$ & $\begin{array}{l}67 \cdot 4 \\
63 \cdot 1 \\
70 \cdot 6 \\
55 \cdot 4 \\
61 \cdot 9 \\
54 \cdot 5 \\
76 \cdot 0 \\
62 \cdot 2 \\
61 \cdot 6 \\
62 \cdot 2 \\
63 \cdot 2 \\
59 \cdot 1 \\
68 \cdot 7 \\
78 \cdot 5 \\
57 \cdot 4 \\
61 \cdot 0 \\
74 \cdot 3 \\
73 \cdot 3 \\
72 \cdot 2 \\
79 \cdot 8 \\
73 \cdot 1 \\
80 \cdot 7 \\
66 \cdot 2\end{array}$ & $\begin{array}{l}68 \cdot 1 \\
67 \cdot 7 \\
73 \cdot 7 \\
61 \cdot 1 \\
65 \cdot 0 \\
55 \cdot 2 \\
77 \cdot 3 \\
64 \cdot 3 \\
62 \cdot 9 \\
66 \cdot 8 \\
65 \cdot 0 \\
61 \cdot 7 \\
76 \cdot 7 \\
80 \cdot 7 \\
63 \cdot 5 \\
62 \cdot 3 \\
76 \cdot 6 \\
75 \cdot 8 \\
75 \cdot 6 \\
80 \cdot 1 \\
75 \cdot 3 \\
81 \cdot 7 \\
69 \cdot 0\end{array}$ & $\begin{array}{l}69 \cdot 4 \\
71 \cdot 0 \\
74 \cdot 0 \\
62 \cdot 3 \\
70 \cdot 5 \\
55 \cdot 9 \\
78 \cdot 2 \\
66 \cdot 1 \\
67 \cdot 6 \\
68 \cdot 5 \\
67 \cdot 0 \\
64 \cdot 5 \\
80 \cdot 3 \\
82 \cdot 9 \\
68 \cdot 7 \\
73 \cdot 0 \\
78 \cdot 5 \\
82 \cdot 5 \\
78 \cdot 8 \\
80 \cdot 4 \\
78 \cdot 3 \\
82 \cdot 7 \\
72 \cdot 6\end{array}$ & $\begin{array}{l}70 \cdot 9 \\
71 \cdot 8 \\
74 \cdot 3 \\
63 \cdot 7 \\
72 \cdot 7 \\
62 \cdot 9 \\
82 \cdot 5 \\
68 \cdot 5 \\
73 \cdot 0 \\
72 \cdot 7 \\
69 \cdot 5 \\
66 \cdot 6 \\
81 \cdot 8 \\
83 \cdot 8 \\
71 \cdot 1 \\
76 \cdot 1 \\
79 \cdot 6 \\
84 \cdot 4 \\
80 \cdot 7 \\
85 \cdot 6 \\
83 \cdot 2 \\
85 \cdot 6 \\
76 \cdot 6\end{array}$ & $\begin{array}{l}67 \cdot 0 \\
69 \cdot 1 \\
71 \cdot 0 \\
61 \cdot 9 \\
68 \cdot 7 \\
58 \cdot 5 \\
73 \cdot 2 \\
66 \cdot 3 \\
69 \cdot 0 \\
66 \cdot 7 \\
62 \cdot 1 \\
64 \cdot 3 \\
68 \cdot 4 \\
78 \cdot 3 \\
63 \cdot 7 \\
68 \cdot 7 \\
74 \cdot 2 \\
72 \cdot 3 \\
71 \cdot 2 \\
79 \cdot 3 \\
71 \cdot 1 \\
72 \cdot 7 \\
63 \cdot 2\end{array}$ & $\begin{array}{l}64 \cdot 7 \\
64 \cdot 1 \\
59 \cdot 3 \\
54 \cdot 2 \\
56 \cdot 0 \\
53 \cdot 4 \\
63 \cdot 2 \\
59 \cdot 1 \\
54 \cdot 9 \\
54 \cdot 8 \\
55 \cdot 7 \\
55 \cdot 0 \\
58 \cdot 4 \\
73 \cdot 4 \\
52 \cdot 4 \\
59 \cdot 8 \\
73.2 \\
71 \cdot 6 \\
69.9 \\
76.7 \\
66.5 \\
71 \cdot 8 \\
60.8\end{array}$ & $\begin{array}{l}49 \cdot 1 \\
51 \cdot 7 \\
52 \cdot 8 \\
55 \cdot 0 \\
45 \cdot 6 \\
49 \cdot 1 \\
53 \cdot 1 \\
44 \cdot 8 \\
49 \cdot 7 \\
55 \cdot 0 \\
49 \cdot 1 \\
50 \cdot 8 \\
41 \cdot 4 \\
52 \cdot 7 \\
48 \cdot 8 \\
50 \cdot 4 \\
45 \cdot 3 \\
50 \cdot 2 \\
50 \cdot 4 \\
55 \cdot 1 \\
49 \cdot 0 \\
50 \cdot 3 \\
50 \cdot 6\end{array}$ & $\begin{array}{l}43 \cdot 4 \\
39 \cdot 7 \\
39 \cdot 5 \\
46 \cdot 3 \\
42 \cdot 5 \\
41 \cdot 1 \\
44 \cdot 0 \\
40 \cdot 1 \\
38 \cdot 3 \\
38 \cdot 2 \\
38 \cdot 2 \\
38 \cdot 5 \\
40 \cdot 4 \\
41 \cdot 9 \\
43 \cdot 8 \\
43 \cdot 2 \\
41 \cdot 0 \\
40 \cdot 1 \\
43 \cdot 9 \\
45 \cdot 5 \\
38 \cdot 0 \\
42 \cdot 1 \\
46 \cdot 9\end{array}$ & $\begin{array}{l}153 \cdot 8 \\
141 \cdot 1 \\
144 \cdot 4 \\
156 \cdot 0 \\
150 \cdot 0 \\
153.2 \\
147 \cdot 1 \\
151.7 \\
148 \cdot 6 \\
155 \cdot 7 \\
154.7 \\
154 \cdot 1 \\
152.5 \\
148 \cdot 1 \\
150 \cdot 8 \\
141.5 \\
147 \cdot 0 \\
147 \cdot 3 \\
153 \cdot 2 \\
137.2 \\
149.0 \\
142.8 \\
149.3\end{array}$ & $\begin{array}{l}148 \cdot 6 \\
136 \cdot 9 \\
144 \cdot 1 \\
155 \cdot 9 \\
146 \cdot 3 \\
145 \cdot 2 \\
146 \cdot 3 \\
149 \cdot 0 \\
144 \cdot 0 \\
151 \cdot 1 \\
145 \cdot 6 \\
150 \cdot 9 \\
149 \cdot 0 \\
141 \cdot 5 \\
146 \cdot 2 \\
141 \cdot 9 \\
140 \cdot 0 \\
140 \cdot 5 \\
149 \cdot 1 \\
133 \cdot 6 \\
146 \cdot 4 \\
138 \cdot 2 \\
146 \cdot 9\end{array}$ & $\begin{array}{l}70 \cdot 0 \\
64 \cdot 6 \\
71 \cdot 2 \\
64 \cdot 4 \\
65 \cdot 8 \\
64 \cdot 6 \\
57 \cdot 6 \\
58 \cdot 8 \\
57 \cdot 8 \\
59 \cdot 0 \\
64 \cdot 0 \\
59 \cdot 2 \\
60 \cdot 0 \\
60 \cdot 8 \\
64 \cdot 4 \\
63 \cdot 4 \\
63 \cdot 6 \\
64 \cdot 6 \\
66 \cdot 2 \\
65 \cdot 8 \\
69 \cdot 0 \\
66 \cdot 2 \\
64 \cdot 4\end{array}$ & $\begin{array}{l}46 \cdot 4 \\
36 \cdot 8 \\
38 \cdot 6 \\
32 \cdot 2 \\
34 \cdot 6 \\
32 \cdot 4 \\
28 \cdot 6 \\
31 \cdot 2 \\
31 \cdot 4 \\
30 \cdot 6 \\
39 \cdot 8 \\
30 \cdot 4 \\
35 \cdot 8 \\
31 \cdot 4 \\
32 \cdot 8 \\
30 \cdot 0 \\
30 \cdot 6 \\
31 \cdot 8 \\
30 \cdot 0 \\
36 \cdot 0 \\
39 \cdot 8 \\
38 \cdot 0 \\
33.0\end{array}$ & $\begin{array}{l}63 \cdot 6 \\
65 \cdot 6 \\
68 \cdot 8 \\
64 \cdot 4 \\
64 \cdot 6 \\
63 \cdot 8 \\
58 \cdot 0 \\
61 \cdot 6 \\
56 \cdot 0 \\
60 \cdot 8 \\
65 \cdot 4 \\
58 \cdot 4 \\
59 \cdot 8 \\
63 \cdot 6 \\
63 \cdot 4 \\
63 \cdot 6 \\
63 \cdot 8 \\
63 \cdot 8 \\
66 \cdot 0 \\
65 \cdot 8 \\
68 \cdot 6 \\
65 \cdot 2 \\
62 \cdot 4\end{array}$ & $\begin{array}{l}38 \cdot 6 \\
33 \cdot 4 \\
38 \cdot 6 \\
33 \cdot 4 \\
36 \cdot 4 \\
34 \cdot 6 \\
25 \cdot 8 \\
31 \cdot 2 \\
30 \cdot 2 \\
29 \cdot 8 \\
37 \cdot 2 \\
28 \cdot 0 \\
34 \cdot 6 \\
32 \cdot 6 \\
34 \cdot 0 \\
30 \cdot 8 \\
32 \cdot 4 \\
31 \cdot 6 \\
34 \cdot 0 \\
33 \cdot 0 \\
39 \cdot 0 \\
33 \cdot 6 \\
31 \cdot 2\end{array}$ \\
\hline $\begin{array}{l}\text { Mean } \\
\text { (SD) }\end{array}$ & $\begin{array}{c}62 \cdot 0 \\
(8 \cdot 4)\end{array}$ & $\begin{array}{c}67 \cdot 0 \\
(7 \cdot 6)\end{array}$ & $\begin{array}{c}69 \cdot 8 \\
(7 \cdot 2)\end{array}$ & $\begin{array}{c}72 \cdot 7 \\
(7 \cdot 1)\end{array}$ & $\begin{array}{c}75 \cdot 5 \\
(6 \cdot 8)\end{array}$ & $\begin{array}{c}68 \cdot 7 \\
(5 \cdot 0)\end{array}$ & $\begin{array}{c}\mathbf{6 2} \cdot 1 \\
(7 \cdot 3)\end{array}$ & $\begin{array}{c}49 \cdot 9 \\
(3 \cdot 2)\end{array}$ & $\begin{array}{c}41 \cdot 6 \\
(2 \cdot 6)\end{array}$ & $\begin{array}{c}149 \cdot 2 \\
(4 \cdot 7)\end{array}$ & $\begin{array}{c}145 \cdot 0 \\
(4 \cdot 5)\end{array}$ & $\begin{array}{c}63 \cdot 7 \\
(3 \cdot 6)\end{array}$ & $\begin{array}{c}34 \cdot 0 \\
(4 \cdot 2)\end{array}$ & $\begin{array}{c}63 \cdot 3 \\
(3 \cdot 0)\end{array}$ & $\begin{array}{c}33 \cdot 2 \\
(3 \cdot 2)\end{array}$ \\
\hline
\end{tabular}

*Conversion factor to SI units: $1 \mathrm{~mm} \mathrm{Hg}=0.133 \mathrm{kPa}$ 


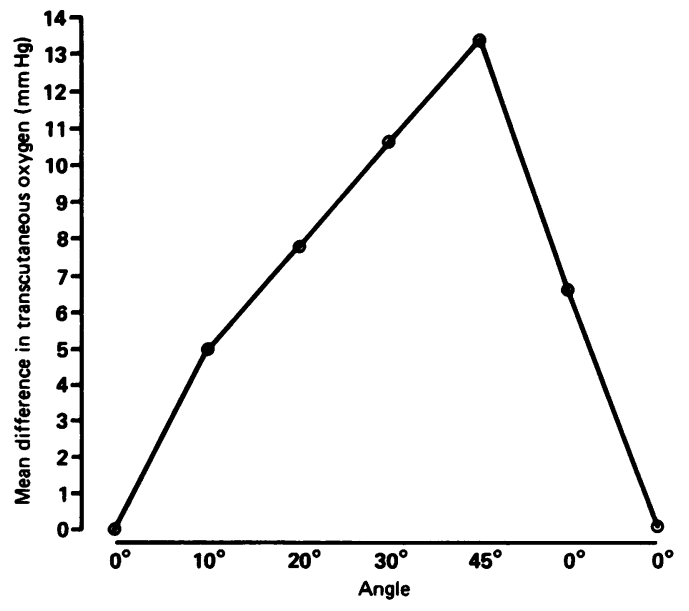

Differences in oxygenation expressed as differences among means for the group of 23 neonates at various tilts. The point of reference is the mean oxygenation ( $O$ difference) at the $0^{\circ}$ angle. The differences between 0 and $10^{\circ}=4 \cdot 6^{\circ}(95 \%$ CI 3.2 to 6.1); between 0 and $20^{\circ}=7.8^{\circ}$ (95\% CI 6.1 to 9.5); between 0 and $30^{\circ}=10.7^{\circ}(95 \%$ CI 8.6 to 12.9; and between 0 and $45^{\circ}=13.5^{\circ}(95 \% \mathrm{CI} 11.4$ to 15.7) $-p<0.01$ in all cases (Student's unpaired t test). (Conversion factor to SI units: $1 \mathrm{~mm} \mathrm{Hg}=0.133 \mathrm{kPa}$.)

Table 2 Percentage gastric residue at 30 minutes at $10^{\circ}$ and $45^{\circ}$ angles in the 10 neonates studied in part 2

\begin{tabular}{|c|c|c|c|}
\hline \multirow{2}{*}{$\begin{array}{l}\text { Case } \\
\text { No }\end{array}$} & \multicolumn{2}{|c|}{ Gastric residue } & \multirow{2}{*}{$\begin{array}{l}\text { Difference between } \\
10^{\circ} \text { and } 45^{\circ} \\
\text { of original meal }\end{array}$} \\
\hline & $10^{\circ}$ & $45^{\circ}$ & \\
\hline $\begin{array}{r}1 \\
2 \\
3 \\
4 \\
5 \\
6 \\
7 \\
8 \\
9 \\
10\end{array}$ & $\begin{array}{l}49 \cdot 5 \\
59 \cdot 7 \\
35 \cdot 2 \\
43.2 \\
50.7 \\
38.0 \\
50 \cdot 3 \\
28 \cdot 1 \\
40.9 \\
38.0\end{array}$ & $\begin{array}{l}47 \cdot 6 \\
43 \cdot 0 \\
29.0 \\
40.8 \\
43 \cdot 0 \\
34 \cdot 8 \\
38.5 \\
21 \cdot 8 \\
39.5 \\
35.0\end{array}$ & $\begin{array}{r}1.9 \\
16.7 \\
6.2 \\
2.4 \\
7.7 \\
3.2 \\
11.8 \\
6.3 \\
1.4 \\
3.0\end{array}$ \\
\hline
\end{tabular}

Table 3 Weekly weight gain during third, fourth, and fifth weeks at $10^{\circ}$ and $45^{\circ}$, and differences observed

\begin{tabular}{|c|c|c|c|c|c|c|c|c|c|c|c|c|}
\hline \multirow[t]{3}{*}{$\overline{\text { Week }}$} & \multicolumn{12}{|c|}{ Case No and weight gain (g) } \\
\hline & \multicolumn{2}{|l|}{$\bar{l}$} & \multicolumn{2}{|l|}{2} & \multicolumn{2}{|l|}{3} & \multicolumn{2}{|l|}{4} & \multicolumn{2}{|l|}{5} & \multicolumn{2}{|l|}{6} \\
\hline & $10^{\circ}$ & $45^{\circ}$ & $10^{\circ}$ & $45^{\circ}$ & $10^{\circ}$ & $45^{\circ}$ & $10^{\circ}$ & $45^{\circ}$ & $10^{\circ}$ & $45^{\circ}$ & $10^{\circ}$ & $45^{\circ}$ \\
\hline $\begin{array}{l}\text { Third } \\
\text { Fourth } \\
\text { Fifth }\end{array}$ & $\begin{array}{r}150 \\
0 \\
150\end{array}$ & $\begin{array}{r}0 \\
180 \\
0\end{array}$ & $\begin{array}{r}100 \\
0 \\
150\end{array}$ & $\begin{array}{r}0 \\
200 \\
0\end{array}$ & $\begin{array}{r}140 \\
0 \\
130\end{array}$ & $\begin{array}{r}0 \\
240 \\
0\end{array}$ & $\begin{array}{r}160 \\
0 \\
230\end{array}$ & $\begin{array}{r}00 \\
280 \\
0\end{array}$ & $\begin{array}{r}0 \\
220 \\
0\end{array}$ & $\begin{array}{r}230 \\
0 \\
240\end{array}$ & $\begin{array}{r}0 \\
180 \\
0\end{array}$ & $\begin{array}{r}210 \\
0 \\
190\end{array}$ \\
\hline $\begin{array}{c}\text { Differences: } \\
10^{\circ}-45^{\circ} \\
45^{\circ}-10^{\circ}\end{array}$ & & $\begin{array}{r}-30 \\
30\end{array}$ & & $\begin{array}{r}-100 \\
50\end{array}$ & & $\begin{array}{r}-100 \\
110\end{array}$ & & $\begin{array}{r}-120 \\
50\end{array}$ & & $\begin{array}{r}10 \\
-20\end{array}$ & & $\begin{array}{r}30 \\
-10\end{array}$ \\
\hline
\end{tabular}

decrease in gastric residue at 30 minutes (expressed as a percentage of the initial test meal) when the angle of tilt increased (table 2).

Using a paired Student's $t$ test the mean of the differences was 6.1 with $95 \%$ CI of 2.5 to 9.6 $(\mathbf{p}<0.01)$.

PART 3

The weekly weight gain at $10^{\circ}$ and $45^{\circ}$ was assessed in six neonates only. Median birth weight was $1195 \mathrm{~g}$ (range 800-1300), median gestational age 29 weeks (range 26-32), and male to female ratio $1: 1$. The relatively small number of neonates studied was dictated by the reluctance of parents to agree for their babies to be tilted to a high angle for prolonged periods of time.

Table 3 shows the weekly weight gain at $10^{\circ}$ and $45^{\circ}$. In each neonate in either sequence the biggest weight gain was observed at $45^{\circ}$. The difference in weight gain between $10^{\circ}$ and $45^{\circ}$ ranged from $10 \mathrm{~g}$ (case 5) to $120 \mathrm{~g}$ (case 4). No side effects were seen and, in particular, no oedema was observed. However a mild nappy rash was seen in four of the neonates at $45^{\circ}$, probably as a result of pressure and irritation of the nappy area.

\section{Discussion}

The optimal nursing position for very low birthweight infants has still to be decided. In previous studies the focus was mainly on the effects of postural changes around the horizontal axis of the body. It was shown that the prone position offered certain advantages over the supine mainly in two areas-respiratory performance and gastric emptying. In the prone position ventilation and lung mechanics improved $^{2}$ as well as oxygenation ${ }^{10}{ }^{11}$ without the respiratory rate being significantly affected by the change in posture. Yu showed that gastric emptying was quicker in the prone position than in the supine. ${ }^{3}$

The effects that may occur on physiological functions when the body is tilted from the horizontal towards the vertical plane have been little studied in neonates. In 1962 the shift of lung volume with tilting was measured in normal newborn infants ${ }^{4}$ to evaluate the effect of gravity in achieving adequate artificial respiration (which had been shown to be possible in adults). ${ }^{12}$ It was noted that the respiratory frequency tended to decrease when the infants were tilted head up though no actual data were provided. More recently the effect of postural change on tidal volume, inspiratory and expiratory duration, minute ventilation, and end tidal carbon dioxide tension was studied in term infants. ${ }^{13}$ It was observed that both the inspiratory and expiratory times increased in the upright position. These findings are relevant to the decrease in respiratory rate at increased angles that we observed in the present study.

It was also found that tilting newborn infants towards the upright position generally resulted in increased end expiratory lung volume. ${ }^{13}$ Recently the effect of tilting on oxygenation on both term and preterm infants was studied by raising them head up to $30^{\circ}$ and $20^{\circ}$, respectively. Oxygenation improved with tilting, and this was more pronounced among preterm infants in whom transcutaneous oxygen measurements between $0^{\circ}$ and $20^{\circ}$ increased by a median value of $1 \mathrm{kPa}(7.5 \mathrm{~mm} \mathrm{Hg})$ which is roughly equal to our difference of mean transcutaneous oxygen tensions between $0^{\circ}$ and $20^{\circ}$ $(7 \cdot 8 \mathrm{~mm} \mathrm{Hg})$. As shown in the figure oxygenation from $0^{\circ}$ to $45^{\circ}$ improved in a near linear fashion. A notable difference between that study ${ }^{6}$ and our results is that in contrast to our findings Thoresen et al observed an upward or downward trend of the transcutaneous oxygen read- 
ings depending on whether there was an increase or decrease of tilt. ${ }^{6}$ As previously mentioned we observed no such trend. A possible explanation is that in our study there was a 10 minute 'resting interval' after each change of tilt for the effect of the change of angle on oxygenation to be fully effective before actual readings were recorded.

There is no clear reason as to why oxygenation improves with tilting. Possible explanations include improved ventilation of lower segments of the lungs and better ventilation/perfusion matching. ${ }^{13}$ In addition, at increased tilts diaphragmatic respiration probably becomes more effective as there is less pressure of the viscera on the diaphragm. Functional residual capacity might also improve. It is notable here that return to the pretilt transcutaneous oxygen tensions was not observed immediately after the return to $0^{\circ}$ but at the second set of measurements 30 minutes later.

The effect of head up tilting on blood pressure and heart rate has previously been studied on term neonates. ${ }^{5}$ A transient reduction in arterial pressure was observed 2-9 seconds after the tilt with a return to the pretilt values 4-30 seconds later. A transient increase in heart rate was also found, but this was observed during the tilt and represented an early compensational mechanism for maintenance of cardiac output and thus of systemic pressure. A similar transient increase in heart rate was also observed in our study (although not recorded) during the change of tilt from $0^{\circ}$ to $45^{\circ}$ before the neonates settled at the higher angle when it decreased below the pretilt level.

As early as 1915 the importance of body position with respect to gastric emptying was stressed. ${ }^{14}$ Radiological data after ingestion of a barium meal suggested that the preterm neonate's stomach empties as rapidly as that of a full term infant. ${ }^{15}$ Radiological estimates of barium density are, however, subjective and in addition there is unnecessary and excessive exposure to radiation. Addition of a chemical marker such as phenol red to a standard meal offers a safe and reliable method for estimating the portion of the test meal that remains in the stomach at various times after a feed. ${ }^{3} 1617$ Although as mentioned earlier it is well documented that gastric emptying is better in the prone than the supine position, we were unable to find any systematic study in which gastric emptying was assessed in the prone position at such increased tilts.

We were also unable to find a study in which the weight gain was assessed in relation to changes in posture from the near horizontal towards the near vertical plane. In the absence of appreciable oedema, the increased weight gain observed at $45^{\circ}$ could be explained (at least partly) by the combination of the decrease in respiratory and heart rate, better oxygenation, and quicker stomach emptying.

Two areas that were not investigated in this study were the effect of tilting on apnoea and gastro-oesophageal reflux, conditions that have been shown to be inter-related in very low birthweight infants in whom nursing at increased angles may have an effect. ${ }^{18}$

In conclusion, we believe that nursing stable preterm neonates at a much higher than conventional angle offers some advantages and may be beneficial. Further studies should however be carried out to assess possible problems which may arise by keeping preterm neonates at increased angles for prolonged periods of time before such a policy is adopted.

We are grateful to Professor RDG Milner for valuable comments and advice, and to Dr Diana Elbourne of the National Paediatric Epidemiology Unit, Radcliffe Infirmary, Oxford, for statisical advice and help.

1 Spoelstra AJG, Strikasibhanda S. Dynamic pressure volume relationship of the lung and position in healthy neonates. Acta Paediatr Scand 1973;62:176-80.

2 Hutchison AA, Ross KR, Russell G. The effect of posture on ventilation and lung mechanics in preterm and light for ventilation and lung mechanics in preter

3 Yu VYH. Effect of body position on gastric emptying in the neonate. Arch Dis Child 1975;50:500-4.

4 Avery ME, O'Doherty N. Effects of body tilting on the resting and expiratory position on newborn infants. Pediatrics 1962;29:255-60.

5 Moss AJ, Emmanouilides GC, Monset-Couchard M, Marcano B. Vascular responses to postural changes in normal newborn infants. Pediatrics 1968;42:250-4

6 Thoresen M, Cowan F, Whitelaw A. Effect of tilting on oxygenation in newborn infants. Arch Dis Child 1988;63: $315-7$

7 Hewitt VM. Effect of posture on the presence of fat in tracheal aspirates in neonates. Aust Paediatr $\mathcal{F}$ 1976;12:267.

8 Parkin JM, Hey EN, Clower JS. Rapid assessment of gestational age at birth. Arch Dis Child 1976;51:259-63.

9 Prechtl HFR. The behavioural states of the newborn infant. Brain Res 1974:76:185-212.

10 Martin RJ, Herrell N, Dubin D, Fanaroff A. Effect of supine and prone positions on arterial oxygen tension in the and prone positions on arterial oxygen

11 Wagaman MJ, Shutack JG, Moomjia AS, Schwarz JG, Shaffer JH, Fox WW. Improved oxygenation and lung compliance with prone positioning of the neonates. J Pediatr 1979;94:787-91

2 Colville P, Shugg C, Ferris BG Jr. Effect of body tilting on respiratory mechanics. F Appl Physiol 1956;9:19-24.

13 Stark AR, Waggener TB, Frantz D, Cohlan BA, Feldman HA, Kosch PC. Effect on ventilation of change to the upright posture in newborn infants. $\mathcal{F}$ Appl Physiol 1984 56: 64-71.

14 Smith $\mathrm{CH}$, Le Wald LT. The influence of posture on digestion in infancy. AMA Foumal of Diseases of Children 1915;9:261-82.

15 Schnell NB, Karelitz S, Epstein BS. Radiographic study of rastric emptying in premature infants. $f$ Pediatr 1963:62: 342-7.

16 Husband J, Husband P. Gastric emptying of water and glucose solutions in the newborn. Lancet 1969;ii:409-11.

17 Gupta M, Brans YW. Gastric retention of neonates. Pediatrics 1978;62:26-9.

18 Newell SJ, Booth IW, Morgan MEI, Durbin GM, McNeish AS. Gastro-oesophageal reflux in preterm infants. Arch Dis Child 1989;64:780-6. 